\title{
Business models, value capture, and the digital enterprise
}

\author{
David J. Teece ${ }^{*}$ and Greg Linden
}

\author{
* Correspondence: \\ teece@haas.berkeley.edu \\ Institute for Business Innovation, \\ University of California, Berkeley, \\ F402 Haas School of Business, \\ \#1930, Berkeley, CA 94720-1930, \\ USA
}

\begin{abstract}
Firms across all industries are embracing internet-based digitization strategies to expand or improve their business. In many cases, though, internet-based businesses pursue customer growth ahead of profits. The path to profitability, which is a core element of a business model, should not be an afterthought. A well-designed business model balances the provision of value to customers with the capture of value by the provider. The elements of a business model and the dynamic capabilities that help design, implement, and refine a model for an organization and its business ecosystem are reviewed. The article then translates these concepts with respect to key organizational design decisions such as that of licensing versus practicing an innovation, insourcing versus outsourcing, and building a business ecosystem.
\end{abstract}

Keywords: Business model, Dynamic capabilities, Platform, Business ecosystem, Boundaries of the firm, Value capture

\section{Introduction}

As more and more elements of the physical world become sources of digital data, software is able to analyze, control, and interact with devices, equipment, and people. This has brought economy-wide changes from the disintermediation of traditional media to the introduction of 3D printing in factories. Inside companies, digitization has contributed to new business processes, new business models, and even new managerial models (Birkinshaw and Ansari 2015).

When a new idea is launched, either as a new enterprise or inside an established company, it needs to be supported by a value capture strategy if it is to have a chance of being more than a passing fad. ${ }^{1}$ While this is self-evident for firms with lots of costly tangible (i.e., physical) assets, it is less obvious for creative firms, including pioneering born-digital companies, which, once the software has been built, often have low or zero marginal costs associated with providing a service. Such companies can be tempted to follow the path of the handful of successful web-based firms that built a large following by giving away a product before deciding how best to leverage their success. The reality, though, is that far more digital companies have made an initial splash only to fail in finding a way to monetize their user base.

Existing companies making physical products that launch a new digital platform, such as an automobile manufacturer providing in-vehicle mobile transactions, present an intermediate case. The company may already have income-statement discipline, but

(c) The Author(s). 2017 Open Access This article is distributed under the terms of the Creative Commons Attribution 4.0 International License (http://creativecommons.org/licenses/by/4.0/), which permits unrestricted use, distribution, and reproduction in any medium, provided you give appropriate credit to the original author(s) and the source, provide a link to the Creative Commons license, and indicate if changes were made. 
it may be tempted to subsidize the new business for an indefinite period in order to enable learning about digital markets and/or to block competing services from encroaching on its space.

Concern about how to capture value from internet-based activities is almost as old as the World Wide Web (e.g., Ghosh 1998). The original Napster, launched in 1999, was an early example, pioneering peer-to-peer file sharing with huge uptake but no expressed value capture model. The challenges quickly became apparent, including the danger of being late in a winner-take-all market niche and the difficulty of differentiating a product in a digital marketplace where potential customers can easily make detailed feature and price comparisons.

Ultimately, any privately offered digital service must pay its own way, directly or indirectly, by capturing a share of the value it creates if it is to be a sustainable business. Competition has become more global, technology more widely dispersed, and business ties more complex, requiring managers to think systemically about how they will accomplish this. The question addressed in this article is "how can companies, especially in the digital realm, gain confidence that they are on a path to profitability when they launch a business?"

While there is never any guarantee that a new business will be, or will remain, profitable, certain steps entrepreneurs can take in the early stages of creating a business will improve its chances. An essential step is taking the time to think through a business model.

A good business model explains how and why customers, suppliers, and complementors interact with the company through the digital interface. As circumstances change, it provides guidance as to the ways the value architecture can be altered and a systemic framework for maintaining overall coherence.

This paper begins by briefly examining the way competition has become more volatile and fast-paced in the digital era. It then introduces the business model concept as a system-level framework for navigating the next-generation competitive landscape by connecting innovation to value capture, including how an organization's dynamic capabilities are used for business model design and implementation. The subsequent section focuses directly on some of the organizational design aspects of the business model, particularly whether an innovation should be exploited purely through licensing, how to draw the boundaries of the firm, and how to use a platform to leverage a business ecosystem. A final section summarizes the key points.

\section{Next-generation competition}

The pace of technological and business innovation seems to have accelerated in recent decades, with the result that sustainably profitable business models are harder than ever to craft. The Internet in particular enables the creation of new types of businesses and allows them to achieve global reach almost instantly. Traditional definitions of "an industry" are becoming outdated as digitization and networking drive convergence across numerous formerly separate realms of activity including banking, IT, advertising, social media, print, broadcasting, timekeeping, mapping, and insurance.

Many established companies are experimenting with the new possibilities in much the same way as start-ups. General Motors, for instance, is experimenting with a new model of car ownership that, for a monthly fee, allows customers to switch in and out 
of different types of Cadillac up to 18 times a year rather than own a single car (Colias 2017). Other firms, like Blockbuster Video, proved unable to respond innovatively and have vanished.

The nature of competition today is so different from the primarily scale-based competition of the previous century that it deserves to be called next-generation competition (Teece 2012a). Next-generation competition is changing the way businesses compete, collaborate, and operate. In particular, the acceleration of competition places a premium on rapidly implementing (and continuously updating) novel business models.

The salient characteristics of next-generation competition include:

\section{- Dynamic competition}

In standard formulations, such as Michael Porter's "Five Forces" (Porter 1980), competition is determined primarily by the structure of input and end-user markets. Innovation is absent from the model, and structural change is rare. Today, incumbent firms struggle to gain durable advantage (D'Aveni et al. 2010). Disruptive innovation from start-ups and entry by firms from once-separate industries brings new competitive pressure that undermines existing business models. In 2009, RIM, the developer of BlackBerry mobile devices, was the second-most profitable company in the cell phone business. Following the successful entry of Apple, a computer company, and Google, an internet search company, into the mobile phone business, it remains an open question whether RIM can even survive. It is now primarily a software company, having sold its BlackBerry handset brand to a new entrant from China, TCL, in 2016.

\section{- A semi-globalized world}

While the world remains in many ways at best semi-globalized (Ghemawat 2003), it is nonetheless a much more complex landscape today than even 20 years ago. For the latter half of the twentieth century, competitors to US firms were based in the USA, Europe, or Japan. Now globally competitive firms have emerged from Taiwan, South Korea, China, and other countries. A corollary of this is that the potential sources of innovation are also more dispersed. Firms need to optimize their costs globally and, if they decide to compete overseas, must learn what adaptations of their initial business model are needed in each new market.

\section{- Multi-invention contexts}

Textbook treatments of innovation often assume that products depend on one, or a few, patented inventions, trade secrets, and trademarks. It has, however, been true for years that products of any complexity-either because of the number of parts or the number of functions-may read on hundreds, if not thousands, of patents, as well as numerous trade secrets. The smartphone is a contemporary example of this "multi-invention context" involving a mind-numbing range of patents for displays, processing, networking, design, and much more (Somaya et al. 2011). In the digital and ecommerce realm, an ever-expanding number of patents for software and business methods provide countless potential stumbling blocks for new ideas (Bessen 2012). 
- Business ecosystems

Competition is no longer so much firm against firm as it is ecosystem against ecosystem (Moore 1993). A business ecosystem contains a number of firms that work together (and also compete) to create and sustain new markets and new products. The co-evolution of the system is typically reliant on the technological leadership of one or two firms that provide a platform around which other ecosystem members, providing inputs and complementary goods, align their investments and strategies. The value capture component of a business model must find an acceptable balance between profits for the focal firm and the profitability of the firm's ecosystem partners.

\section{- Organizational capabilities}

With next-generation competition, businesses need to think differently about their sources of advantage. A critical weakness in accounting and other financial perspectives is their limited ability to recognize the competitive significance of intangible assets, despite the fact that such assets are increasingly the essence of the contemporary business enterprise (Teece 2015). The most recognized of these assets is a firm's intellectual property, such as patents and trade secrets. But there are other, and arguably more important, types of intangibles. In the management literature, a key idea of the 1990s was that a company's strength lay in its "core competences," the technologies and know-how that underlie and bring coherence to the company's businesses (Prahalad and Hamel 1990). Since then, attention has increasingly turned to higher-level competences called "dynamic capabilities" (Teece et al. 1997). These enable a company to coordinate its various tangible and intangible resources to accomplish tasks such as new product development and business model design. Dynamic capabilities also contribute to the alignment of production plans with customer needs (and willingness to pay) by activities that can be summarized as "sensing, seizing, and transforming" (Teece 2007, 2014). These capabilities are embedded in both organizational routines and managerial cognition.

To summarize, firms today must navigate a more complex innovation environment, build and maintain a richer set of alliances, and counter a wider range of competitors from both expected and unexpected quarters than ever before. It is vital for managers to understand and augment the full range of their organization's capabilities if they are to design and implement innovative business models that track the evolution of technology and consumer demand.

\section{Business models}

Business models, one of the most vital tools for articulating the "architectural" design of a business so as to manage the complexity of next-generation competition, merit a closer look. In this section, we consider their definition, design, and implementation.

\section{a. Definition}

There are multiple definitions of the business model concept in use, and several comparisons have been published (e.g., Birkinshaw and Ansari 2015). The definition used here is that a business model "articulates the logic ... that demonstrates how a business creates and delivers value to customers [and] outlines the architecture of revenues, costs, and profits associated with ... delivering that value" (Teece 2010, p. 173). 
Without the right balance between the creation, delivery, and capture of value, the model will not be in operation very long, at least not by a for-profit enterprise.

A business model has many moving parts, all of which must work together congruently. The model as a whole must also be aligned with the organization's strategy, culture, and resources. These relationships cannot be optimized just through data analytics. Good business model design depends as much on art and intuition as it does on science and analysis.

A compact but fairly comprehensive list of business model components is provided by Schön (2012). His schema is similar to that of Osterwalder and Pigneur (2010) but further compiled into three main categories. Slightly adapted, the list is as follows:

Value proposition: product and service, customer needs, geography

Revenue model: pricing logic, channels, customer interaction

Cost model: core assets and capabilities, core activities, partner network

Extensions are possible. For example, some business model definitions incorporate strategy (e.g., Chesbrough and Rosenbloom 2002). While strategic analysis, such as which customer segments to target in which order, is inevitably tied to business model design, it as an analytically separate and more detailed exercise (Teece 2010).

With a digital setting in mind, El Sawy and Pereira (2013) included the design of a service platform and customer interface as part of business model design. This introduced questions such as whether the digital platform would be based on open or proprietary standards, and how easily the interface could be customized by users. These sorts of product design detail choices, part of the model's value proposition, will not be pursued further in the present article.

\section{b. Business model design}

The process of designing a particular business model is typically engaged by sensing the existence of customers with an unmet (or poorly met) need who are willing and able to pay for a potential product or service. A successful business model will provide a customer solution that can support a price high enough to cover all costs and yield profit that is at least sufficient to support the business and its growth.

Sensing takes place at all levels of the organization, with lower levels helping to provide information and insights about external developments to middle and top managers. A manager looking to profit in a particular technology area needs "generative sensing" through which various hypotheses about the underlying state of consumer demand are tested until a set of options can be validated (Dong et al. 2016).

Most "new" (to a given firm) business models will be similar to older ones, involving a permutation or hybridization of existing models. A typical example would be a firm that excels in a particular area of operations, e.g., running a restaurant chain, and then leverages its expertise into a services business such as supply chain consulting. While there are a finite number of business model types, the opportunities for recombinations are virtually endless.

A firm's seizing capabilities come into play for the crafting of a revenue mechanism and the planning of the organization's value chain, including the designation of which activities will be internalized and which will be left to outside suppliers. An important early decision is whether to test a business model on a segment of the potential user base before the new product or service is introduced more widely. This can help prove 
the concept behind the business model and allow an opportunity to make adjustments before large-scale commitments are made. However, it can also allow potential rivals valuable information and time to better position themselves to compete.

Tested or not, business models are seldom successful "out of the box" and must be fine-tuned-and sometimes completely overhauled-before they enable the business to become a profit engine. Start-ups generally find transformation easier than do mature firms because they have fewer established assets and procedures to reengineer. The "lean start-up" model that has spread well beyond Silicon Valley includes the capacity to "pivot," i.e., to quickly test, discard, and replace ideas and business models that do not work (Ries 2011). This is especially relevant for software-intensive Internet-based business models (where pivoting is relatively easy because much software can be repurposed) and in circumstances where social media can provide fast feedback.

Business models can last for years or even decades, but they all have finite life spans. When changes are sensed in technology, consumer demand, or the competitive landscape, business model revision is needed. This is best undertaken before the need for change becomes obvious. Proactive sensing of the need for change is a dynamic capability that must be cultivated and built into the organization's structure. Scanning and interpretive processes can be embedded throughout the organization, with open communication channels leading back to upper management so that information flows to where it is needed (Teece 2012b).

Sensing must consider more than just technology; it entails awareness of large market trends and numerous other factors. A famous example is Kodak, which invented a mass-market film-based camera in the early 1900s and refined its designs incrementally over decades as it made most of its money from selling photographic film. Although a Kodak engineer demonstrated a digital camera prototype in 1975, the company's film business was so profitable that it only slowly explored the digital camera opportunity, failing to recognize the technology's disruptive potential. It continued to invest in $R \& D$, with results that included the first megapixel image sensor. However, Kodak's management had no sense of urgency, perhaps fearing cannibalization. In consequence, digital camera technologies were commercialized most effectively by other companies. Digital cameras came to market in the 1990s and thereafter followed the same "smaller, better, cheaper" trajectory as personal computers. Kodak responded in the 2000s to the fasterthan-expected decline of its film business with entries in the digital camera and color printer markets, but it struggled to distinguish its products and finally declared bankruptcy in 2012. Although other leading camera firms also came under extreme pressure at that time, had Kodak's management moved more quickly, it arguably would have bought itself valuable time to explore other options.

In some cases, an existing business model can be rejuvenated by altering only some of its elements. For example, Rolls-Royce changed its revenue model in the 1960s to "power-by-the-hour", or "jet engines as a service" (Rolls-Royce 2012). The customer, instead of paying the high fixed cost of the engine up front, pays only for the hours when the engine is operational. Rolls-Royce has strong incentives to keep the customer's engines in good working order, as opposed to the old system in which its incentive was purely to sell engines. Furthermore, an hourly contract enables Rolls-Royce to dampen rivalry from third-party service providers, helping it capture the lucrative service relationship that has always been more profitable than selling the engines themselves. 
Of prime import is how the elements of a business model create (or destroy) differentiation from competitors in the market. Although many business models, such as power-by-the-hour, can be copied by rivals, in practice it may take many years for this to occur. Rivals may calibrate their opportunities differently, and they may lack the organizational adaptability to switch business models. In other words, they may have weaker dynamic capabilities.

Pioneering a new business model is particularly important when the market has network effects and "installed base" characteristics such that the more users who are engaged, the greater the value associated with the platform (Katz and Shapiro 1994). In such cases, winner-take-all, or winner-take-most, competition is more likely (Teece 2013). This helps to explain why early Internet companies like Amazon that survived initial industry shakeouts have developed formidable leadership positions.

\section{c. Business model implementation}

In an existing company, the introduction of a new business model can prove challenging because of a cultural mismatch, the ability of existing businesses to influence budgets, or other reasons that start-ups do not face. This is particularly true when adding a next-generation business into a company that has been competing in more traditional ways. One solution is to set the new business apart, with its own premises and possibly even a different incentive system. This can work provided there is high-level support for the new venture. The capability of an established firm to experiment with new businesses while not undermining its existing revenue sources has been called ambidexterity (O’Reilly and Tushman 2004).

When a new business model is implemented in a start-up or within an established firm, the organization's transforming capabilities come into play to configure, or reconfigure, the necessary resources and maintain organizational coherence. Radical business model transitions that change numerous elements of an existing model at the same time are unlikely to succeed without major financial resources and a steady commitment. For example, most taxicab companies are not attempting to replicate the ridesharing capabilities of Uber or Lyft because those models are based primarily on software and data skills unavailable at low-tech cab companies. However, staying within their existing business model, taxis have improved quality as shown by a reduction in complaints in the New York City and Chicago areas (Wallsten 2015). Although a capability such as data analytics can be acquired, integrating an unrelated capability into an existing organization is challenging at best, disastrous at worst.

Business model implementation, like transformation more generally, involves closing capability gaps between the firm's current activities and those required to enact the new business model (Teece forthcoming). The gap closure can be accomplished through internal or external means, with the decision depending on a number of variables, including the strategic relevance of the capability, the time that would be required to "build" it, and the availability of the capability from third parties.

The gap identification process begins by examining the match between a proposed business model and the firm's existing capabilities. An analysis of existing capabilities needs an objective point of view that is detailed and realistic. Organizational instincts tend to compel the exaggeration of current capabilities. The true magnitude of a gap may become apparent only after an organization falls short in executing a strategic 
initiative. The early phase of a project may be satisfactory, but as it progresses, problems begin to crop up, the senior team has to get more and more involved, and the goal slips further away. Management may have thought that a particular capability, such as supply chain management, was in place only to discover that it was inadequate to the needs of a new product or strategy.

To build a new capability, the people must be chosen correctly in terms of skills, creativity, and readiness to learn. Moreover, teams need time and guidance to develop their routines and develop working relationships. Even if much of the capability resides in a new piece of specialized equipment, it takes time for it to be fully understood and integrated into new routines then diffused to the divisions and geographies where it is needed. Many projects and programs fail because of an organization's inability to develop and integrate the capabilities needed to deliver on a new objective. While building capabilities is hard, there is a silver lining; if well-built, they can be difficult for others to imitate and provide a basis for competitive advantage.

Many "ordinary" capabilities for production and administration are unlikely to be differentiators. They can be outsourced or developed to best-practice levels with the aid of consultants.

When a required new capability is less mundane, questions of how to acquire, whom to hire, and what to measure become harder to answer. Filling capability gaps involves more time, effort, and expense the larger the "distance" that separates the desired capability from what the firm is currently doing in technological, marketing, and business model terms (Teece forthcoming).

Radical business model innovations are particularly challenging to implement because they involve addressing multiple gaps simultaneously, and the effort and attention needed to do so is non-linear with closing individual gaps. Large organizations are complex systems where every change can have a systemic impact on social, economic, and other dimensions.

Above all, the closing of capability gaps requires leadership by managers. An organization will not embrace transformation unless its managers are clearly committed. Employees will not engage in the necessary learning unless they are encourage$\mathrm{d}$-and given the means-to do so. During the initial learning phase, the emphasis should be on effectiveness and improvement. A premature focus on financial performance can impair the ability to deliver better results in the longer run.

Capabilities can sometimes be obtained through merger or acquisition, but taking this perceived shortcut can introduce other problems. An acquired capability still needs to be learned and absorbed by the acquiring firm's existing employees, which reduces the time saved. Moreover, management, prior to the acquisition, needs a deep understanding of the capability and how excellence is measured, failing which a hasty acquisition could turn out to disappoint.

\section{Designing an organization and its ecosystem}

Many new business models are based on a key business or technological innovation. A framework that can assist in choosing some of the organizational design aspects of a business model is the Profiting From Innovation (PFI) model (Teece 1986, 2006). The PFI model, in the first instance, helps an innovator identify the key considerations for deciding a fundamental business model question: whether to license the innovation to 
other companies or to develop and commercialize it internally. The PFI model also helps to decide which functions to outsource and how external complementarities can be harnessed.

\section{a. Licensing}

Licensing (or selling an early-stage start-up) potentially surrenders a larger share of the potentially available profits from an innovation but may be the surest route to monetization when direct commercialization by the innovator poses too many challenges for the inventor, e.g., when the capability (and financing) gaps are too numerous and large (see Teece 1986, Figure 9). Moreover, for an innovation with multiple uses, licensing can potentially cover more of the potential applications than the innovating firm could exploit on its own.

However, licensing is subject to numerous pitfalls. A key question before choosing this business model concerns the strength of the relevant intellectual property regime. If the innovation can be imitated and intellectual property protection in the relevant jurisdiction is weak, then licensing may not be viable, and the innovator may be forced to integrate in order to have a decent chance of capturing some value.

The strength of intellectual property (IP) such as patents, trade secrets, and copyrights is often illusory. For instance, patents are not self-enforcing; patent infringement and trade secret misappropriation is frequent, sometimes leading to costly litigation. Moreover, many patents can be "invented around" at modest costs (Mansfield 1985; Mansfield et al. 1981). The pioneer's business challenge is usually quite a hard one; followers often have it easier. To help with appropriability, the pioneer of a core technology can try to seek complementary patents on new features and/or processes and, in some cases, on designs, but these activities may delay efforts at licensing or commercialization.

A licensing model may also require that technology be transferred to licensees. That, too, involves costs. Moreover, the technology's use may not be easy to monitor (Somaya et al. 2011). A further complication in recent times is the emergence of cybertheft and other cybersecurity problems. Being secure to market must often take precedence over being first to market.

b. Internal development and the boundaries of the firm

When a pure licensing model is rejected, the innovator must invest in direct (or joint-venture) commercialization. A key insight from the PFI model is that successfully commercializing an innovation requires complementary assets and technologies, often including other innovations, in order to provide a reasonably complete value proposition to users. Complements that exist and are competitively supplied can generally be outsourced or left to the ecosystem that builds products and services around the innovator's platform. Various other types of complements require special attention:

- A complement might not yet exist and need to be developed. That adds risk and delay to the commercialization path.

- A complement may be highly specialized to the innovation being commercialized. If this is supplied by another firm, that firm may hold too much leverage over the innovator. 
- A complement may be in short supply or can become so in the event the innovation proves successful. This is a "bottleneck" that can attract a large share of the profit stream if not owned or otherwise controlled by the innovator.

- A complement may be systemically linked to the focal innovation so that the two need to co-develop for future iterations of the product or service offering (de Figueiredo and Teece 1996). Leaving the complement in a separate firm risks losing control of the technological trajectory (Chesbrough and Teece 1996).

The issue of timing must also be considered. Decisions about where to draw the firm's boundaries lead to a list of investments in assets and capabilities that need to be made to implement particular business models. Are other companies racing the innovator to market with similar products? Given the amount of time the contemplated investments would take, are rivals better positioned to compete? A positive answer here leads to a consideration of licensing.

This question of where to draw the boundaries of the firm's activities is seldom straightforward and may need to be revisited periodically. Even a start-up offering a purely digital service must decide which corporate functions, such as HR and ad placement, can be rented from other service providers without harming its ability to build up its differentiated value proposition. And the challenge is even greater for products that straddle the digital-physical divide, even for formidable digital innovators like Google/Alphabet. In 2009, Google launched a project to develop technology for self-driving vehicles. In 2014, it announced that it was launching its own fleet of custom-designed driverless vehicles without steering wheel or pedals, suggesting that it might be becoming a car company (Walsh 2014). In 2017, not long after being established as a separate division called Waymo within Google's Alphabet holding company, the company announced that, while it would not be bringing its own cars to market, it would be offering other car companies a platform consisting of its software and a set of sensors (radar, lidar, and vision modules) that it had designed (Higgins 2017).

\section{c. Digital platforms and business ecosystems}

If one applies the PFI model, many complements are likely left to other firms to provide. These firms, which may supply inputs, accessories, or ancillary services, add value to the focal firm's innovation and constitute the innovator's business ecosystem.

At the heart of most ecosystems lies the innovator's platform. Although platforms are not entirely new, digital technologies have vastly expanded their reach by allowing the easy inter-operability of systems based on common standards. As a result, products that were once separate are more easily integrated, creating opportunities for new business models.

A platform is a combination of hardware and software that provides standards, interfaces, and rules that allow providers of complements to add value and interact with each other and/or users. Collectively, the platform innovator(s) and the complementors constitute an ecosystem that depends on continued innovation and maintenance of the platform by its owner(s) for success.

There are at least two basic types of digital platform, of which there are also numerous hybrid combinations (Evans and Gawer 2016). The first kind, a transaction platform, facilitates exchanges by otherwise fragmented groups of consumers and/or firms. 
A paradigm example is eBay, which allows huge numbers of individual sellers and buyers located anywhere in the world to find one another with an ease that was previously unimaginable. While digitization has enabled transaction platforms in a growing range of industries, this transactional type of platform is not entirely new. For example, the credit card industry has long provided a viable payment option that merchants will accept, that banks will join by issuing cards and processing transactions, and that cardholders find of value. However, the newer digital transaction platforms present an unprecedented opportunity to accumulate and leverage the knowledge voluntarily shared by its users (Brousseau and Penard 2007).

An innovation platform provides a base technology and a distribution system to which other companies can add their own innovations, increasing the value for the system as a whole. Apple's "app" ecosystem is a well-known, and much copied, example of this. The PC ecosystem based on Intel chips and Microsoft software was an earlier instance.

Platform owners of either type must attract complementors. While the process is somewhat different depending on whether the complementors are partner businesses or individual consumers, both types of partner need to see a compelling value proposition to adopt the platform. Platform owners must also decide whether or not to impose an exclusivity requirement, such as an exclusive distribution agreement by a content provider with a digital media outlet. In other cases, a complementor (e.g., an application software provider) can participate in multiple ecosystems (e.g., both Apple's iOS and Google's Android).

The potentially disastrous effects of a failure to connect with ecosystem partners is demonstrated by the problems that a Japanese wireless carrier, NTT Docomo, had when it tried to take its domestic success overseas. Docomo's i-mode system, launched in 1999, became one of the first successful wireless data services. The i-mode service, limited by the $2 \mathrm{G}$ cellular technology of the time, allowed keypad phones to access email and certain specially redesigned web pages. It also included a simplified version of an app store through which third parties provided i-mode users with paid services and content and shared the profits with NTT. Although i-mode was wildly successful-and profitable-in Japan, efforts to export it failed. NTT invested heavily in overseas partnerships, including a nearly $\$ 10$ billion investment in AT\&T Wireless in 2000, but failed to convince them to adopt the integrated i-mode business model (Kushida 2011). NTT also faced an equipment problem in export markets because the Japanese companies making i-mode phones had no presence outside Japan, where the wireless standards at the time were incompatible with those of most other countries. NTT had difficulty convincing the leading non-Japanese phone manufacturers, particularly thendominant Nokia, to develop i-mode-compatible devices. Another element of the ecosystem, imode compatible content, was also in short supply. In 2002, NTT's partners in the USA and Europe began to roll out i-mode-based services, but the uptake by consumers was poor, and in 2002, Docomo took a write-down of more than $\$ 1$ billion on its overseas investments.

\section{Conclusions}

Global competition is placing a higher premium than ever before on astute management. Strategy and organizational design choices are immensely complicated in many markets today. Digitization, a driver of next-generation competition, adds flexibility but also speeds up the pace of competition. Tasks such as calibrating threats from rivals, cultivating cultural awareness, forming a patent strategy, and developing a portfolio of 
organizational capabilities must all be done more quickly and with less margin for error than ever before. In markets with network effects, the need to move early and rapidly must be balanced with the need for thorough analysis and thoughtful experimentation. An understanding of system-level concepts can help managers build robust, coherent organizations and strategies.

A critical tool for mapping a pathway to profit through the obstacle course of next-generation competition is the business model. It is in some sense the skeleton around which a company structures an internal organization, builds capabilities, and, of course, formulates strategy so that the company can make its way in the market. A robust business model provides a solid basis for success. Key principles include:

- Good business model design requires deep knowledge of customer needs and the technological and organizational resources that might meet those needs.

- Most new business model designs involve the hybridizations of others. An understanding of current business models at work in the market is essential.

- The elements of a business model should be mutually reinforcing.

- Business models evolve. They need to change in response to competition, imitation, or other changes outside the firm. In the longer term, they eventually need to be replaced.

- The introduction of a new business model into an existing organization is often difficult and may require a separate organizational unit.

The design and implementation of a business model requires strong dynamic capabilities for sensing, seizing, and transforming. Customer needs must be identified, products developed, revenue and pricing mechanisms designed, and capability gaps closed. These are not one-time actions; they are processes involving learning loops that contribute to continually adjusting the business model so as to maintain the organization's competitive edge. Conjectures must be formed and tested. Failures must be recognized, analyzed, and used as a springboard to new learning.

The Profiting From Innovation model provides an organized approach to thinking through critical business model issues. Is a pure licensing approach viable? Which assets will be in short supply? Which capabilities can be safely outsourced? How can a platform attract a robust business ecosystem?

Innovations do not exist in isolation; they interact or compete with numerous others. Changing one element of a business model (e.g., distribution channels) requires changing others (e.g., customer interaction, pricing). Companies do not go to market in isolation; in most cases, their products and services become more valuable to customers when combined with the products and services of other firms. Managers today must think systemically. Those who comprehend and implement system-level concepts such as business model, dynamic capabilities, and Profiting From Innovation will be less likely to lose themselves inside the forest among the trees.

\section{Endnotes}

${ }^{1}$ This has been a long-standing focus of Teece's research, as reflected in Teece (1986, 1988, and 2006). 


\section{Acknowledgements}

The authors are grateful to two anonymous reviewers for helpful feedback.

\section{Authors' contributions}

The paper was developed and written collaboratively by both authors. Both authors read and approved the final manuscript.

\section{Competing interests}

The authors declare that they have no competing interests.

Received: 30 March 2017 Accepted: 19 July 2017

Published online: 24 August 2017

\section{References}

Bessen J (2012) Generation of software patents. Boston University Journal of Science Technology Law 18(2):241-261 Birkinshaw J, Ansari S (2015) Understanding management models: going beyond "what" and "why" to "how" work gets done in organizations. In: Foss NJ, Saebi T (eds) Business model innovation: the organizational dimension. Oxford University Press, Oxford, pp 85-103

Brousseau E, Penard T (2007) The economics of digital business models: a framework for analyzing the economics of platforms. Rev Netw Econ 6(2):81-114

Chesbrough H, Rosenbloom RS (2002) The role of the business model in capturing value from innovation: evidence from Xerox Corporation's technology. Ind Corp Chang 11(3):529-555

Chesbrough HW, Teece DJ (1996) Organizing for innovation: when is virtual virtuous? Harv Bus Rev 74(1):65-73

Colias, M. 2017. GM tries a subscription plan for Cadillacs. wsj.com, March 19. https:/www.wsj.com/articles/gm-tries-asubscription-plan-for-cadillacsa-netflix-for-cars-at-1-500-a-month-1489928401 (Accessed 21 Mar 2017)

D'Aveni R, Dagnino BG, Smith KG (2010) The age of temporary advantage. Strateg Manag J 31(13):1371-1385 de Figueiredo JM, Teece DJ (1996) Mitigating procurement hazards in the context of innovation. Ind Corp Chang 5(2):537-559 Dong A, Garbuio M, Lovallo D (2016) Generative sensing. Calif Manag Rev 58(4):97-117

El Sawy OA, Pereira F (2013) Business modelling in the dynamic digital space: an ecosystem approach. Springer, Berlin

Evans PC, Gawer A (2016) The rise of the platform enterprise: a global survey. Center for Global Enterprise, New York http://www.thecge.net/wp-content/uploads/2016/01/PDF-WEB-Platform-Survey_01_12.pdf (Accessed 16 Feb 2016)

Ghemawat P (2003) Semiglobalization and international business strategy. J Int Bus Stud 34(2):138-152

Ghosh S (1998) Making business sense of the Internet. Harv Bus Rev 76(2):126-135

Higgins, T. 2017. Alphabet Inc.'s self-driving car unit creates its own sensor package. wsj.com, January 8. http://www.wsj. com/articles/alphabet-inc-s-self-driving-car-unit-creates-its-own-sensor-package-1483912457 (Accessed 20 Jan 2017)

Katz ML, Shapiro C (1994) Systems competition and network effects. J Econ Perspect 8(2):93-115

Kushida, KE (2011) Leading without followers: how politics and market dynamics trapped innovations in Japan's domestic "Galapagos" telecommunications sector. J Industry Competition Trade 11(3):279-307.

Mansfield E (1985) How rapidly does new industrial technology leak out? J Ind Econ 34(2):217-223

Mansfield E, Schwartz M, Wagner S (1981) Imitation costs and patents: an empirical study. Econ J 91(364):907-918

Moore JF (1993) Predators and prey: a new ecology of competition. Harv Bus Rev 71(3):75-83

O'Reilly CA, Tushman ML (2004) The ambidextrous organization. Harv Bus Rev 82(4):74-81

Osterwalder A, Pigneur Y (2010) Business model generation: a handbook for visionaries, game changers, and challengers. Wiley, Hoboken, NJ

Porter ME (1980) Competitive strategy: techniques for analyzing industries and competitors. Free Press, New York

Prahalad CK, Hamel G (1990) The core competence of the corporation. Harv Bus Rev 68(3):79-91

Ries E (2011) The lean startup: how today's entrepreneurs use continuous innovation to create radically successful businesses. Crown Business, New York

Rolls-Royce, 2012. Rolls-Royce celebrates 50th anniversary of Power-by-the-Hour. Press Release, October 20, http://www. rolls-royce.com/media/press-releases/yr-2012/121030-the-hour.aspx (Accessed 26 Jan 2016)

Schön O (2012) Business model modularity—a way to gain strategic flexibility? Consult Manag 56(2):73-78

Somaya D, Teece DJ, Wakeman S (2011) Innovation in multi-invention contexts: mapping solutions to technological and intellectual property complexity. Calif Manag Rev 53(4):47-79

Teece DJ (1986) Profiting from technological innovation. Res Policy 15(6):285-305

Teece DJ (1988) Capturing value from technological innovation: integration, strategic partnering, and licensing decisions. Interfaces 18(3):46-61

Teece DJ (2006) Reflections on profiting from innovation. Res Policy 35(8):1131-1146

Teece DJ (2007) Explicating dynamic capabilities: the nature and microfoundations of (sustainable) enterprise performance. Strateg Manag J 28(13):1319-1350

Teece DJ (2010) Business models, business strategy and innovation. Long Range Plan 43(2):172-194

Teece DJ (2012a) Next-generation competition: new concepts for understanding how innovation shapes competition and policy in the digital economy. J Law Econ Policy 9(1):97-118

Teece DJ (2012b) Dynamic capabilities: routines versus entrepreneurial action. J Manag Stud 49(8):1395-1401

Teece DJ (2013) The new managerial economics of firm growth: the role of intangible assets and capabilities. In: Thomas CR, Shughart WF (eds) The Oxford handbook of managerial economics. Oxford University Press, Oxford, pp 278-301

Teece DJ (2014) The foundations of enterprise performance: dynamic and ordinary capabilities in an (economic) theory of firms. Acad Manag Perspect 28(4):328-352

Teece DJ (2015) Intangible assets and a theory of heterogeneous firms. In: Bounfour A, Miyagawa T (eds) Intangibles, market failure and innovation performance. Springer, New York, pp 217-239 
Teece, DJ (forthcoming) A capability theory of the firm: an economics and (strategic) management perspective. Accepted in New Zealand Economic Papers.

Teece DJ, Pisano G, Shuen A (1997) Dynamic capabilities and strategic management. Strateg Manag J 18(7):509-533

Wallsten S (2015) The competitive effects of the sharing economy: how is Uber changing taxis? Technology Policy Institute, Washington, DC https://techpolicyinstitute.org/wp-content/uploads/2015/06/thecompetitive-effects-of-the-2007713.pdf (Accessed 21 Mar 2017)

Walsh, D. 2014. Roush to assemble Google self-driving cars in Allen Park, sources say. Crain's Detroit Business, May 28. http://www.crainsdetroit.com/article/20140528/NEWS/140529850/roush-to-assemble-google-selfdriving-cars-in-allen-park-sources-say (Accessed 20 Jan 2017)

Submit your manuscript to a SpringerOpen ${ }^{\circ}$ journal and benefit from:

- Convenient online submission

- Rigorous peer review

- Open access: articles freely available online

- High visibility within the field

- Retaining the copyright to your article

Submit your next manuscript at $\boldsymbol{s p r i n g e r o p e n . c o m ~}$ 